\title{
Very-High-Speed Slotless Permanent-Magnet Motors: Analytical Modeling, Optimization, Design, and Torque Measurement Methods
}

\author{
Pierre-Daniel Pfister and Yves Perriard, Senior Member, IEEE
}

\begin{abstract}
This paper presents a very-high-speed (VHS) slotless permanent-magnet motor design procedure using an analytical model. The model is used to design the optimal prototype (target: $200 \mathrm{kr} / \mathrm{min}, 2 \mathrm{~kW}$ ). The multiphysics analytical model allows a quick optimization process. The presented model includes the magnetic fields, the mechanical stresses in the rotor, the electromagnetic power losses, the windage power losses, and the power losses in the bearings. VHS machines need a new torque measurement method. This paper presents the developed method. It also presents a ball bearing friction torque measurement method designed particularly for VHS machines. Remarkably, the method allowed us to design a prototype which operates beyond the target of speed and power. The results given by the model are compared with the measurements of the prototype.
\end{abstract}

Index Terms-Analytical model, ball bearing, inertia, optimization, permanent-magnet (PM) machine, retaining sleeve, slotless machine, synchronous machine, torque measurement methods, very-high-speed (VHS) motor.

\section{INTRODUCTION}

D UE TO THEIR high power density, very-high-speed (VHS) permanent-magnet (PM) motors are increasingly requested on the market. Indeed, as the mechanical power is given by $P=T \omega$, for a given motor volume and torque $T$, the output power and hence power density increase with the rotation speed $\omega$.

The increasing need for low weight, high efficiency, and high power density motors or generators has led to an intense research and development in the field of VHS motor or generator [1]-[7].

The domains of applications of VHS machines are very diversified: automotive industry (supercharger, electrically assisted turbocharger [8], fuel cell compressor [9]), machining industry (machine tool [10], micromachining), home appliance industry (vacuum cleaner), medical industry (micromotors for dental medicine), and other specific applications (compressors, cryocooler [11], vacuum pump, gas turbines [12], [13], flywheels [14]).

Manuscript received December 19, 2008; revised July 9, 2009. First published July 28, 2009; current version published December 11, 2009. This work was supported in part by Moving Magnet Technologies SA and in part by Sonceboz SA.

P.-D. Pfister is with Sonceboz SA, 2605 Sonceboz, Switzerland, and with Moving Magnet Technologies SA, 25000 Besançon, France, and also with the Swiss Federal Institute of Technology, 1015 Lausanne, Switzerland (e-mail: pierre-daniel.pfister@epfl.ch).

Y. Perriard is with the Swiss Federal Institute of Technology, 1015 Lausanne, Switzerland (e-mail: yves.perriard@epfl.ch).

Digital Object Identifier 10.1109/TIE.2009.2027919
The first aspect which is presented in this paper is the design of the high-speed motor. A traditional way to design motors is to perform the optimization using each of its submodels (thermal, mechanical, electromagnetic, etc.) separately and iteratively. This is called a fragmented conception. In this paper, the mechanical optimum for the motor would be to reduce the rotor diameter to diminish the stress in it, but it would reduce the motor torque. The magnetic optimum would be to reduce the air gap, but it would increase the windage power losses. These simple examples show the necessity of having an optimization which uses the complete multiphysics model of the system.

There are at least two different approaches for performing multiphysics systems optimization. The first one is with finite element methods. It has the advantage that it can solve complicated structures, but the required computer time is enormous when there are different physical aspects and different parameters to optimize.

The second method is to create a fully analytical model and to do a mathematical optimization. The advantage of this method is that it is extremely fast. It also gives much more insights in the physics of the system. This method was chosen for the VHS motor development presented in this paper.

The second aspect which is presented in this paper is the measuring process linked with the target speed and power of the machine. The goal is the measurement of a $200000-\mathrm{r} / \mathrm{min}$ $2-\mathrm{kW}$ synchronous machine. Traditional measurement tools are not compatible with such high speeds.

Although many articles have been written about VHS motors in general and VHS slotless PM motors in particular, only a very few teams reached the speed of $200 \mathrm{kr} / \mathrm{min}$ [11], [15].

References [15] and [16] have already presented VHS motor developments. Although the motor model presented in the next paragraphs is general, the goal of the research is to design a motor at much higher power than the cited articles. In addition, in these articles, there are no measurements of the overall efficiency of the motor presented.

Reference [11] presents a motor design of power and speed which are similar to the target of this paper, but it does not present any multiphysics analytical optimization.

The main contributions of this paper are as follows.

1) A designing procedure method which includes both a multiphysics analytical optimization and experimental results of the overall motor power balance.

2) An innovative motor torque measurement method which allows one to validate the model. Although the presented 


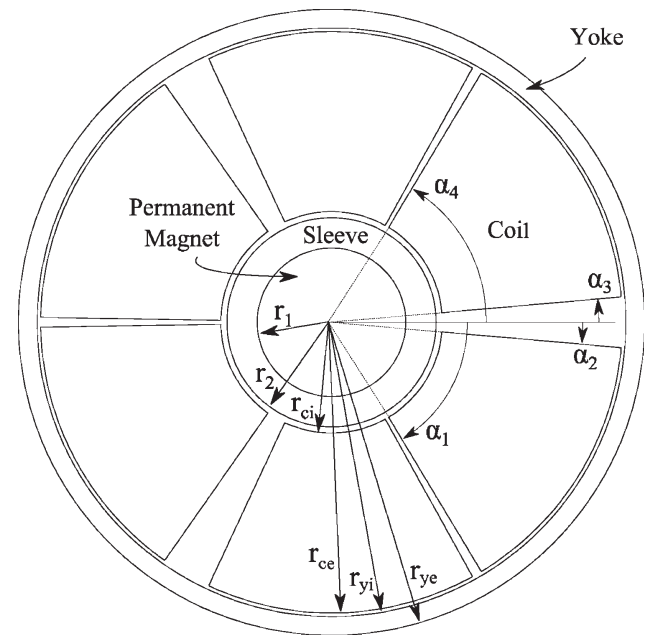

Fig. 1. VHS slotless PM motor structure.

method has similarities with [17], the presented innovations give a much better precision.

3) An innovative ball bearing friction torque measurement method.

\section{Analytical Model}

The analytical model is applied to the motor structure shown in Fig. 1. The geometry is as follows: a PM at the center, a sleeve, an air gap, three coils, and a stator yoke. The goal of the optimization process is to reduce the power losses. The power balance of the motor will be presented first, and the different power losses contributions are presented in the next part of this section.

\section{A. Power Balance}

The power balance is given by

$$
P_{\text {mech }}=P_{\text {in }}-P_{\text {loss }}
$$

with $P_{\text {mech }}$ the output mechanical power, $P_{\text {loss }}$ the power losses, and $P_{\text {in }}$ the motor input power. The total power losses are assumed to be given by

$$
P_{\text {loss }}=P_{w}+P_{\text {bear }}+P_{\text {iron }}+P_{\text {cop }}
$$

with $P_{w}$ the windage power losses, $P_{\text {bear }}$ the bearing power losses, $P_{\text {iron }}$ the iron power losses in the stator, and $P_{\text {cop }}$ the Joule power losses in the coils. $P_{\text {mech }}$ is related to the power $P_{\text {mag }}$ transmitted to the rotor by the currents in the coils

$$
P_{\text {mech }}=P_{\text {mag }}-P_{w}-P_{\text {bear }}-P_{\text {iron }} .
$$

\section{B. Torque Due to the Magnetostatic Fields}

Since the machine is slotless, the gap between the PM and the stator yoke is big. This implies that the magnetic flux density is low in the stator yoke. The yoke can be chosen thick enough so that no magnetic saturation is needed to be considered inside of it. Using the article from Xia et al. [18], the magnetostatic fields are calculated. The torque $T$ produced by the interaction of the current passing through one coil and the PM is calculated as

$$
T=\frac{2 B_{R} J l_{a} r_{1}^{p+1}\left[\frac{r_{\mathrm{ce}}^{p+2}-r_{\mathrm{ci}}^{p+2}}{r_{\mathrm{yi}}^{2 p}(p+2)}+g\left(p, r_{\mathrm{ce}}, r_{\mathrm{ci}}\right)\right] f\left(\alpha_{i}, \theta, p\right)}{(1+p)\left[\left(1+\mu_{r}\right)+\left(1-\mu_{r}\right)\left(\frac{r_{1}}{r_{\mathrm{yi}}}\right)^{2 p}\right]}
$$

with $B_{R}$ the PM remanent field, $\mu_{r}$ the PM relative permeability, $p$ the number of pole pairs, $J$ the instantaneous current density averaged in a coil section, $r_{1}$ the outer radius of the PM, $r_{\mathrm{ci}}$ the inner radius of the coil, $r_{\mathrm{ce}}$ the outer radius of the coil, $r_{\mathrm{yi}}$ the inner radius of the stator yoke, $\theta$ the rotor position, $l_{a}$ the active length, and

$$
\begin{aligned}
g\left(p, r_{\mathrm{ce}}, r_{\mathrm{ci}}\right)= & \begin{cases}\frac{r_{\mathrm{ce}}^{-p+2}-r_{\mathrm{ci}}^{-p+2}}{-p+2}, & \text { if } p \in \mathbb{N}^{*} \backslash\{2\} \\
\ln \left(\frac{r_{\mathrm{ce}}}{r_{\mathrm{ci}}}\right), & \text { if } p=2\end{cases} \\
f\left(\alpha_{i}, \theta, p\right)= & \sin \left(p\left(\alpha_{4}-\theta\right)\right)-\sin \left(p\left(\alpha_{3}-\theta\right)\right) \\
& -\left(\sin \left(p\left(\alpha_{2}-\theta\right)\right)-\sin \left(p\left(\alpha_{1}-\theta\right)\right)\right)
\end{aligned}
$$

with $\alpha_{i} i=1, \ldots, 4$ the angles which set the dimensions of one coil, as shown in Fig. 1. This torque model is validated through 2-D finite element methods with an error of less than $0.01 \%$. More details about this model can be found in [7].

The current density is assumed to vary as a sinusoidal function of the time. The torque due to the current passing through one coil is maximum when the instantaneous current density is maximum $J_{\max }$ and when the rotor position is such that the total flux passing through the coil is equal to zero. The maximum torque is called $T_{\max } 1 \mathrm{ph}$. With $p=1$ or $p=2$, the power transmitted to the rotor due to the sinusoidal currents passing through the three coils $T_{3 \mathrm{ph}}$ is equal to

$$
P_{\text {mag }}=\frac{3}{2} T_{\max 1 \mathrm{ph}} \omega
$$

with $\omega$ the angular velocity.

\section{Mechanical Stresses}

The mechanical stresses $\left(\sigma_{r}, \sigma_{\alpha}\right)$ are calculated in each of the two layers of the rotor using the equilibrium equation [19] in the polar coordinate system $(r, \alpha)$

$$
\frac{d \sigma_{r}}{d r}+\frac{\sigma_{r}-\sigma_{\alpha}}{r}+F_{r}=0
$$

with $F_{r}$ the radial force density. Hook's law gives the dependence of the strain $\varepsilon$ on the stresses

$$
\begin{gathered}
\varepsilon_{r}=\frac{1}{E}\left(\sigma_{r}-\nu \sigma_{\alpha}\right) \\
\varepsilon_{\alpha}=\frac{1}{E}\left(\sigma_{\alpha}-\nu \sigma_{r}\right)
\end{gathered}
$$

with $E$ Young's modulus and $\nu$ Poisson's ratio. 
In a rotating system, a volume element is subject to the following force:

$$
F_{r}=\rho \omega^{2} r .
$$

The detailed model of the stresses in the rotor is presented in [20].

\section{Electromagnetic Power Losses}

Joule power losses density $p_{\text {cop }}$ in the coils is calculated as

$$
p_{\text {cop }}=\rho_{c} J^{2}
$$

with $\rho_{c}$ the resistivity and $J$ the current density. The Joule power losses $P_{\text {cop }}$ are calculated as

$$
P_{\text {cop }}=\frac{3}{2} \frac{\rho_{c} J_{\max }^{2} V_{c}}{F_{c}}
$$

with $J_{\max }$ the maximum current density averaged over a coil section, $F_{c}$ the coil filling factor, and $V_{c}$ the volume of one coil.

The stator iron power losses $P_{\text {iron }}$ are assumed to be generated only by the PM. Their density $p_{\text {iron }}$ is calculated approximately using the Steinmetz equation

$$
p_{\text {iron }}=c_{1} f^{c_{2}} \hat{B}^{c_{3}}
$$

with $c_{i}, i=1,2,3$ being empirical coefficients given by the manufacturer, $\hat{B}$ the maximum magnetic field, and $f$ the frequency. The same empirical approach, used in [21] for the hysteresis power losses, is used here for the iron power losses. The model yoke thickness is chosen so that $\hat{B}$ is at the saturation limit. $\hat{B}$ is assumed to be constant along a radius. $P_{\text {iron }}$ can be expressed as

$$
P_{\text {iron }}=2 \pi c_{1} f^{c_{2}} l_{a}\left(r_{\mathrm{ye}}-r_{\mathrm{yi}}\right) \hat{B}^{c_{3}}
$$

with $r_{\text {ye }}$ the outer radius of the stator yoke.

The eddy current and hysteresis power losses in the magnet are neglected. The eddy currents in the sleeve and in the coils are also neglected.

\section{E. Windage Power Losses}

The article from Vrancik [22] indicates that the windage power losses $P_{w}$ are calculated as

$$
P_{w}=\pi C_{d} l r_{2}^{4} \omega^{3} \rho_{\text {air }}
$$

with $l$ the length considered, $r_{2}$ the inner radius of the air gap, and $\rho_{\text {air }}$ the air density. The skin friction coefficient $C_{d}$ is calculated using an empirical formula

$$
\frac{1}{\sqrt{C_{d}}}=2.04+1.768 \ln \left(\operatorname{Re} \sqrt{C_{d}}\right)
$$

with $R e$ the Reynolds number

$$
R e=\frac{r_{2} \delta \omega}{\nu}
$$

with $\nu$ the air kinematic viscosity and $\delta$ the air gap.

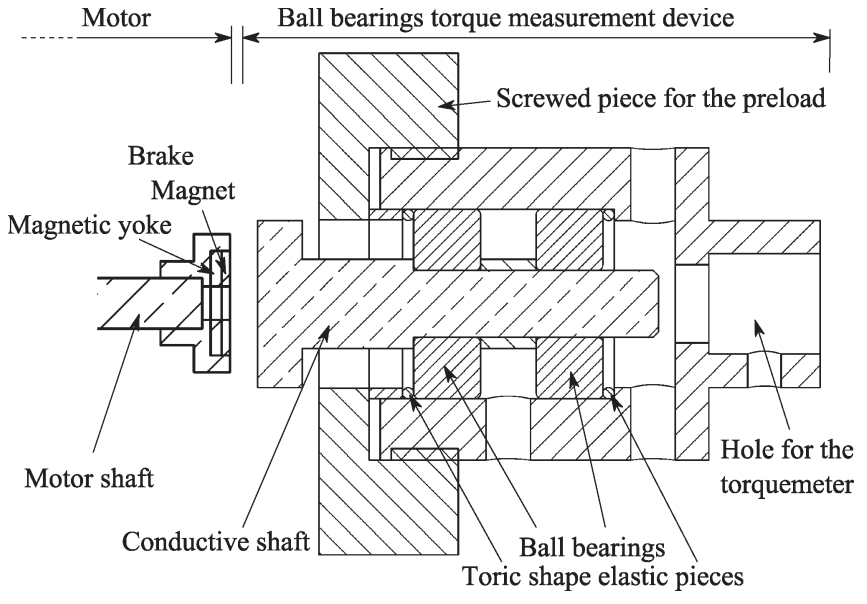

Fig. 2. Bearings friction torque measurement setup: the conductive shaft driven from the left, the two ball bearings, and a hole on the right is for the torquemeter.

\section{F. Ball Bearings Power Losses Model}

In a ball bearing, there are many parameters which influence the friction torque: the dimensions, the rolling paths materials, the balls materials, the contact angles, the construction precision, the speed, the preload, and the lubrication.

Theoretical models are available in the literature [23], [24] to estimate this torque. However, due to the VHSs and the uncertainties of many model parameter values, the accuracy of such models may be poor [25].

Among articles about the use of ceramic ball bearings for high-speed applications [26], there are not many about friction torque. Reference [27] gives an empirical model for a given design and speed range.

Therefore, a setup was done to do an empirical model for the ball bearings considered for the prototype. The model which allows one to calculate the power losses in the bearings $P_{\text {bear }}$ has the following form:

$$
P_{\text {bear }}=c_{4}\left(\frac{f}{1 \mathrm{~Hz}}\right)^{c_{5}} \text {. }
$$

The next section shows the procedure to obtain the two constants $c_{4}$ and $c_{5}$.

\section{BALl BeArings Power Losses}

\section{A. Setup}

As shown in Fig. 2, two ball bearings are mounted on a conductive shaft which is made of aluminum. A multipolar axially magnetized PM is mounted at the end of the shaft of the motor and drives the conductive shaft. Eddy currents are created in the conductive shaft, so the coupling is contactless. The reaction torque $T_{2}$ is measured on the fixed part which surrounds the bearings.

Two toric shape elastic pieces stand at the two sides of the bearings. The preload is adjusted on the bearings through a screwed piece (on the left, in Figs. 2 and 3).

The data of the tested bearings are shown in Table I. 


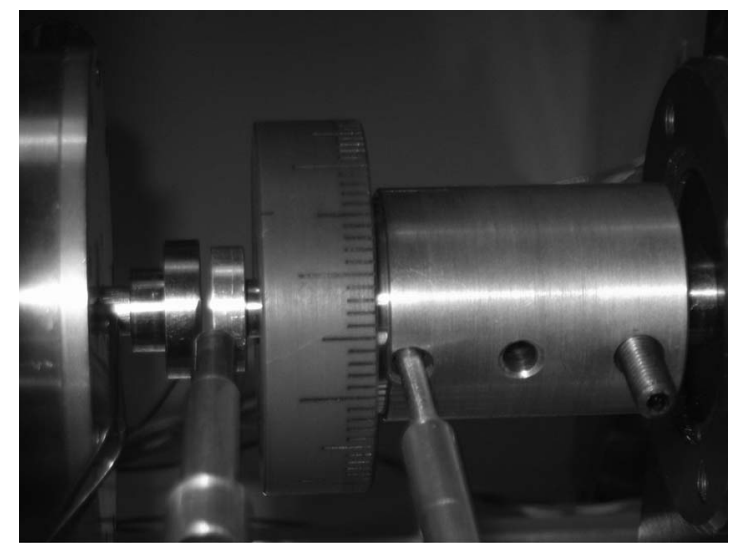

Fig. 3. Picture of the bearing friction torque measurement setup.

TABLE I

Dimensions, Data SheEt Properties, And Measured MOdEL PARAMETERS OF THE BALL BEARINGS

\begin{tabular}{|c|c|c|}
\hline & $\begin{array}{l}\text { Inner diameter } \\
\text { Outer diameter } \\
\text { Axial length } \\
\text { Contact angle } \\
\text { Ball type }\end{array}$ & $\begin{array}{l}6 \mathrm{~mm} \\
17 \mathrm{~mm} \\
6 \mathrm{~mm} \\
15^{\circ} \\
\text { Ceramic }\end{array}$ \\
\hline Preload & $17 \mathrm{mNm}$ & $35 \mathrm{mNm}$ \\
\hline $\begin{array}{l}c_{4} \\
c_{5}\end{array}$ & $\begin{array}{l}1.17 \times 10^{-6} \mathrm{~W} \\
2.153\end{array}$ & $\begin{array}{l}6.12 \times 10^{-6} \mathrm{~W} \\
1.969\end{array}$ \\
\hline
\end{tabular}

\section{B. Measurement Procedure}

As the coupling between the motor shaft and the conductive shaft is done by the mean of eddy currents, there is a speed difference between the two shafts. Let $f$ be the conductive shaft rotation frequency, $f_{m}$ the motor rotor rotation frequency, and $\Delta f$ the frequency difference between them

$$
\Delta f=f_{m}-f .
$$

In order to relate $\Delta f$ to the torque applied on the conductive shaft by the motor shaft, the conductive shaft is fixed $(f=0)$ while the motor is running. The torque $T_{1}$ is measured as a function of $\Delta f=f_{m}$. It gives the slip curve

$$
T_{1}=g_{1}(\Delta f) .
$$

Then, the conductive shaft is set to rotate freely. The motor is driven at different speeds. The reaction torque $T_{2}$ is measured as a function of $f_{m}$

$$
T_{2}=g_{2}\left(f_{m}\right) .
$$

As there is no speed sensor on the conductive shaft, its rotation frequency is deduced using the slip curve

$$
f=f_{m}-g_{1}^{-1}\left(T_{2}\right) .
$$

Using (22) and (23), the friction torque and hence the power losses is deduced as a function of the shaft speed.

The results are shown in Fig. 4. The friction torque of the ball bearings is dependent on the speed and on the preload. The measurements which include the mechanical coupling through the air are fitted using (19). The resulting coefficients are shown in Table I.

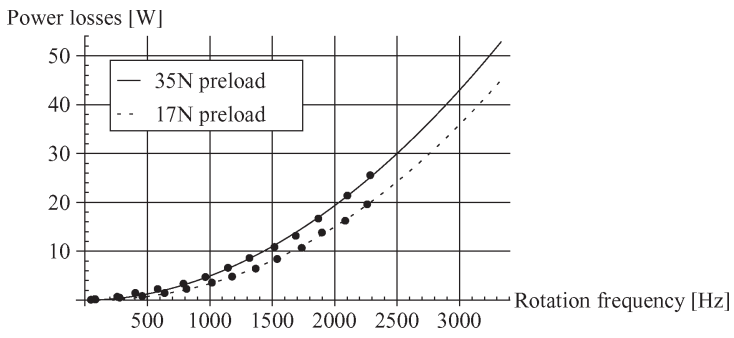

Fig. 4. Power losses in a pair of ball bearings: the dots represent the measurements and the curves represent the deduced model.

\section{Optimization}

\section{A. Optimization Process}

Two commercial software applications are used for the optimization: Pro@DESIGN [28] and Mathematica. Pro@DESIGN includes different optimization algorithms. Some are based on a sequential quadratic programming solver using the partial derivatives and penalty functions. One parameter is chosen to be the objective function and all the others are fixed, constrained in intervals, or free. Mathematica also includes many optimization algorithms. A code in Mathematica was written to handle models with a large number of parameters. The two software applications showed the same results.

The objective function is chosen to be the total power losses shown in (2). This is an indirect way to take into account the thermal aspect of the motor. These losses include the iron power losses in the stator, the Joule power losses in the coils due to the applied current, the windage power losses in the air gap. The eddy current power losses in the rotor are not considered in this paper. The rotor power losses will be considered in a future article. The output power is used as a constraint. In addition, the mechanical model is used as a constraint: The stresses in the center of the PM and at the inner side of the sleeve have to be lower than the maximum stress of the different materials.

The geometrical parameters which are optimized are the following: the outer radius of the PM, the outer radius of the sleeve, the interference between the PM and the sleeve, the air gap, the coil thickness, the angles $\alpha_{1}$ and $\alpha_{2}$, the active length of the motor, and the number of PM pole pairs.

The result of the optimization is shown in Table II. With the given constraints on the active length, a one pole-pair motor is more efficient than a two pole pair.

\section{B. Pareto Frontiers}

The suggested method for designing VHS motors allows one to study Pareto frontiers.

The Pareto frontier defines optimal parameter sets. It is the boundary between the feasible parameter sets and the parameter sets which are not feasible. For example, as shown in Fig. 5, the point of the surface represents the design with the lower possible power losses for a given active length and coil thickness. Below the surface, there is no feasible design. Above the surface, the designs are not optimal.

The Figs. 5-7 are realized by doing 400 optimizations for each figures. Nevertheless, the advantage of the purely analytical method is that it is extremely fast. The time used by the 
TABLE II

Model Constraints And Minimization of the Power Losses

\begin{tabular}{lrl}
\hline \multicolumn{3}{c}{ Model constraints: } \\
\hline PM remanence $\left(B_{R}\right)$ & 1.18 & $\mathrm{~T}$ \\
Outer angle of the coils $\left(\alpha_{4}-\alpha_{1}\right)$ & 1118 & $\circ$ \\
Number of phases & 3 & \\
Mechanical power & 2 & $\mathrm{~kW}$ \\
Speed & 200 & $\mathrm{krpm}$ \\
\hline \multicolumn{3}{c}{ Results of the optimization: } \\
\hline Active length of the motor & 57.6 & $\mathrm{~mm}$ \\
Outer radius of the PM & 5.215 & $\mathrm{~mm}$ \\
Outer radius of the sleeve & 5.715 & $\mathrm{~mm}$ \\
Inner radius of the coils & 8.11 & $\mathrm{~mm}$ \\
Outer radius of the coils & 36.15 & $\mathrm{~mm}$ \\
Inner angle of the coils $\left(\alpha_{3}-\alpha_{2}\right)$ & 23 & $\circ$ \\
Outer angle of the coils $\left(\alpha_{4}-\alpha_{1}\right)$ & 118 & $\circ$ \\
Air gap & 2.395 & $\mathrm{~mm}$ \\
Number of PM pole pairs & 1 & \\
Phase current amplitude (sin wave) & 43.9 & $\mathrm{~A}$ \\
Efficiency & 95.0 & $\%$ \\
Bearings power losses & 53 & $\mathrm{~W}$ \\
Joule power losses & 21 & $\mathrm{~W}$ \\
Air gap power losses & 11 & $\mathrm{~W}$ \\
Iron power losses & 19 & $\mathrm{~W}$ \\
\hline
\end{tabular}

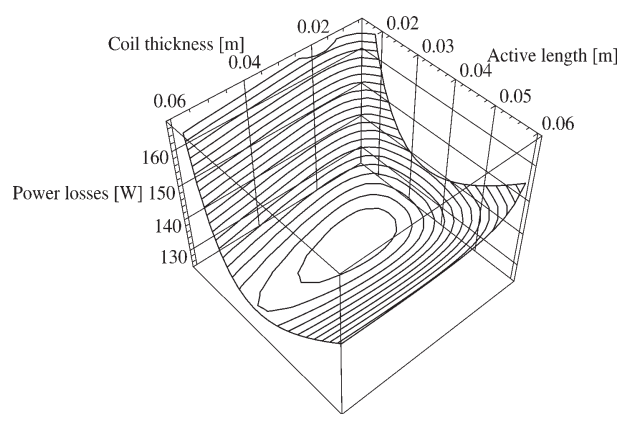

Fig. 5. Pareto frontier of the power losses, the coils thickness, and the air gap. The radial dimensions of the rotor are constrained to be equal to the dimensions of rotor of the prototype presented in Section VI-A.

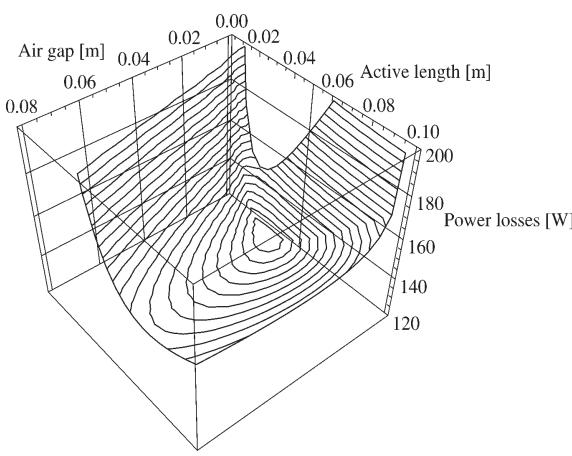

Fig. 6. Pareto frontier of the power losses, the active length, and the air gap. The radial dimensions of the rotor are constrained to be equal to the dimensions of the rotor of the prototype presented in Section VI-A.

Mathematica package for the calculation of the 400 optimizations of Fig. 5 is 23.9 s, Fig. 6: 33.2 s, and Fig. 7: 116.3 s.

In the calculation of Figs. 5 and 6, a constraint is added in the optimization process. The radial dimensions of the rotor are fixed. They are equal to the one of the prototype presented in the next section (Table III). In the calculation of Fig. 7, no extra constraint is added. Since the radial dimensions of the rotor are optimized in this case, it means that the optimization process takes more time. The comparison of Figs. 6 and 7 shows that

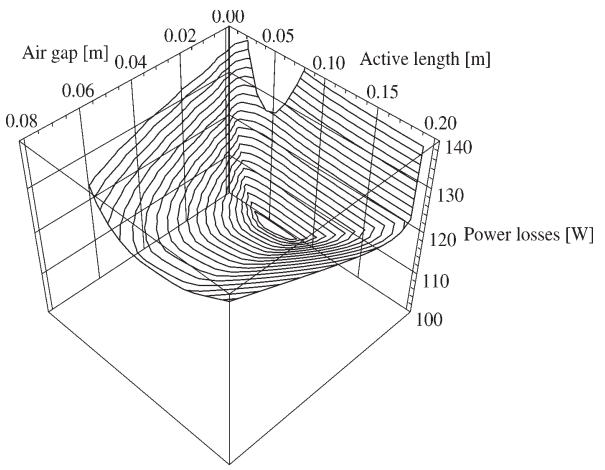

Fig. 7. Pareto frontier of the power losses, the active length, and the air gap. No extra constraint is added on the radial dimensions of the rotor.

TABLE III

Prototype SPECIFICATIONS AND RESUlting DESIGN

\begin{tabular}{lrl}
\hline \multicolumn{3}{c}{ Prototype specifications: } \\
\hline Active length of the motor $\left(l_{a}\right)$ & $\leq 30$ & $\mathrm{~mm}$ \\
Outer angle of the coils $\left(\alpha_{4}-\alpha_{1}\right)$ & $\leq 118$ & $\circ$ \\
$\mathrm{PM}$ & $\mathrm{NdFeB}$ & \\
PM remanence $\left(B_{R}\right)$ & 1.18 & $\mathrm{~T}$ \\
Number of phases & 3 & \\
Mechanical power & 2 & $\mathrm{~kW}$ \\
Speed & 200 & $\mathrm{krpm}$
\end{tabular}

Prototype specifications resulting from the optimization:

Active length of the motor $\quad 30 \mathrm{~mm}$

$\begin{array}{lll}\text { Outer radius of the PM } & 6.244 \mathrm{~mm}\end{array}$

Outer radius of the sleeve $\quad 8.24 \mathrm{~mm}$

Air gap $\quad 1.36 \mathrm{~mm}$

Inner radius of the coils $\quad 9.6 \mathrm{~mm}$

Outer radius of the coils $\quad 16.8 \mathrm{~mm}$

Inner angle of the coils $\left(\alpha_{3}-\alpha_{2}\right) \quad 22 \quad \circ$

Outer angle of the coils $\left(\alpha_{4}-\alpha_{1}\right) \quad 118 \circ$

Number of PM pole pairs

Phase current amplitude (sin wave) $31.1 \quad$ A

Efficiency $\quad 93.7 \%$

Bearings power losses $\quad 53$ W

Joule power losses $\quad 38 \quad$ W

Air gap power losses $\quad 28$ W

Iron power losses

$15 \mathrm{~W}$

the constraint on the radial dimensions of the rotor increases the power losses for high active lengths.

Pareto frontiers are very useful to give an representation of the effect of changes of some parameters.

\section{Motor Torque Measurement}

This method is based only on the inertia of the motor rotor. A coder measures the angular position $\alpha$ of the rotor. The acceleration $\ddot{\alpha}$ of the rotor is related to the frequency $f_{c}$ of the coder with resolution $n$ as

$$
\ddot{\alpha}=\frac{2 \pi}{n} \dot{f}_{c} .
$$

Knowing the inertia $I$, the torque $T$ that needs to be applied to produce the acceleration $\ddot{\alpha}$ is obtained

$$
T=I \ddot{\alpha} .
$$

The inertia of the rotor of the prototype is $I=1.6431 \times$ $10^{-6} \mathrm{~kg} \cdot \mathrm{m}^{2}$. 


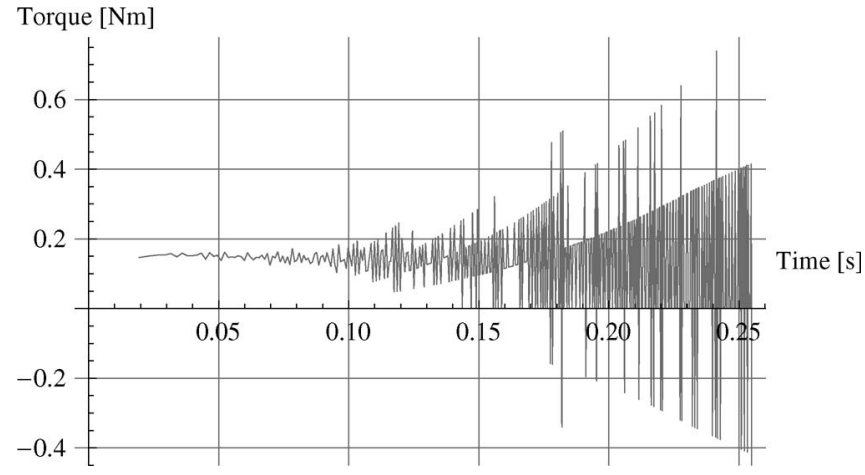

Fig. 8. Motor torque obtained by numerical differentiation. The useful information is covered by noise.

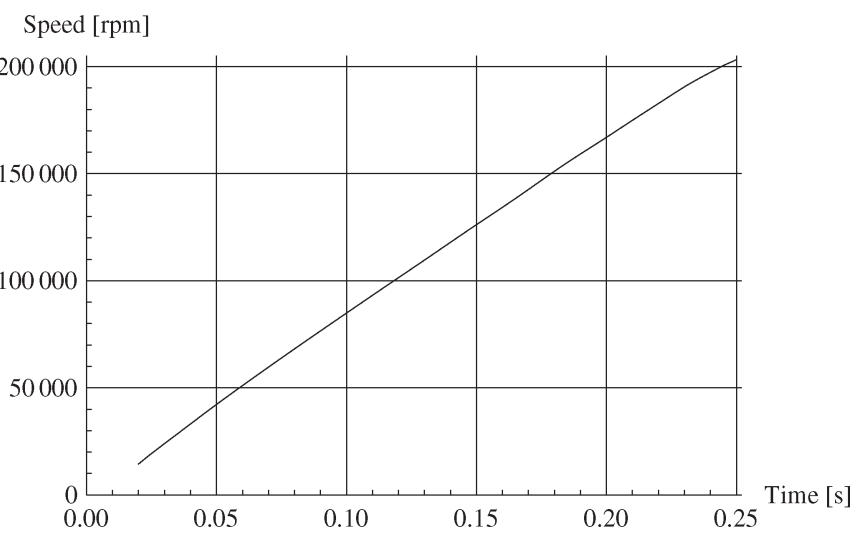

Fig. 9. Speed as the function of time obtained by analytical differentiation.

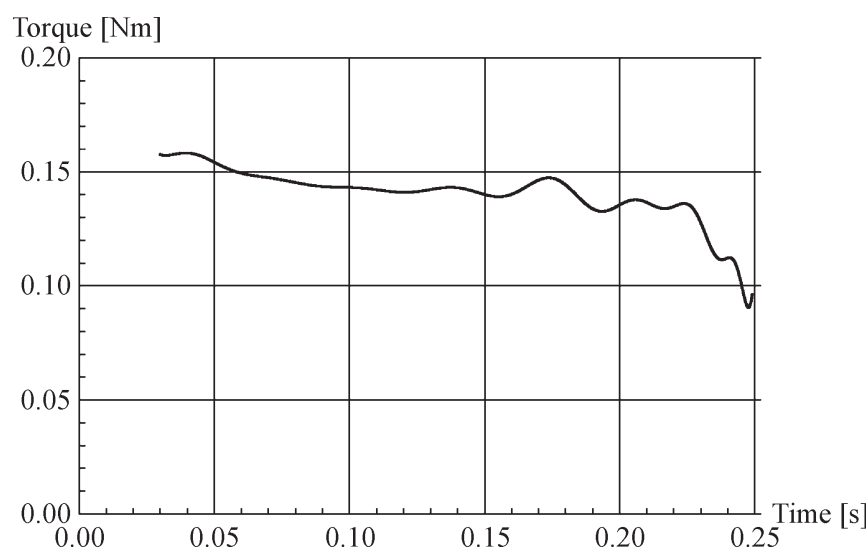

Fig. 10. Torque as a function of time obtained by analytical differentiation.

The value $n$ needs to be compatible with low and high speeds. For the prototype presented in the next section, the angle $\alpha$ is measured by the coder with $n=1$. A numerical differentiation allows one to obtain the rotor speed. Using a numerical differentiation once again, the torque is computed (Fig. 8). The noise in the measurements makes a numerical differentiation useless. As shown in Figs. 8-11, the voltage applied to the power bridge which supplies the prototype is $96 \mathrm{~V}$. The current is limited from 0 to $227 \mathrm{~ms}$.

The solution for eliminating this noise is to do first a polynomial fitting of the curve representing the rotor position as a function of the time and then differentiate analytically. Fig. 9 shows the speed as a function of time. A second analytical

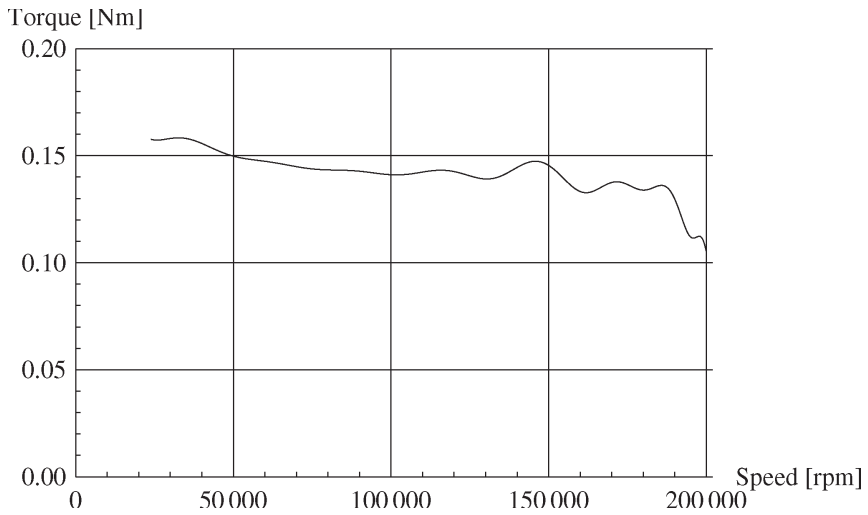

Fig. 11. Torque as a function of speed.

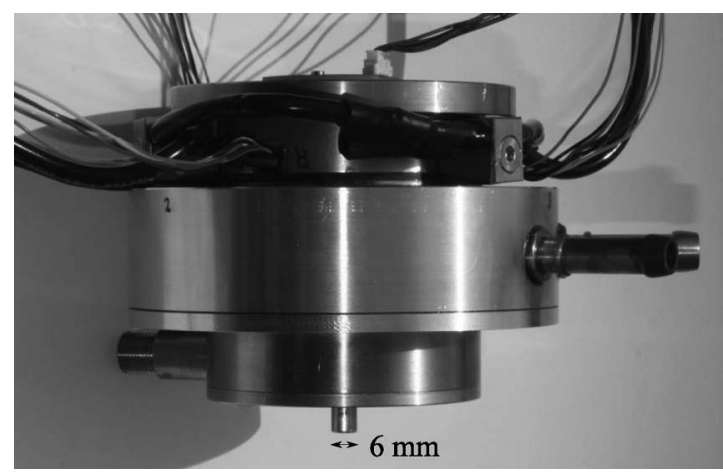

Fig. 12. Picture of the VHS slotless PM prototype.

derivative is calculated to obtain the torque (Fig. 10). This method is powerful to cancel the noise.

Before the fitting, a resampling can be done, because there are more points per unit of time at high speed than at low speed.

The combination of the speed and the torque functions (Figs. 9 and 10) gives the torque versus speed curve. The result obtained is shown in Fig. 11. In this case, the current is limited through an electronic regulation from 0 to $\sim 188 \mathrm{kr} / \mathrm{min}$. It corresponds to the region which is approximately constant.

The advantage of this method is that the complete torque versus speed curve can be measured very rapidly since the whole measure is done in one step.

The disadvantage of this method is that it is very sensitive to the correctness of the calculation of the inertia. Another disadvantage is that it is not possible to measure the torque in a thermically stabilized regime.

\section{EXPERIMENTAL VALIDATION OF THE ANalytical Model}

\section{A. Optimized Prototype}

Because of the mechanical natural frequencies, the active length of the motor was constrained to be smaller or equal to $30 \mathrm{~mm}$. The prototype specifications are presented in Table III. The design resulting from the optimization of the analytical model and some construction constraints are also presented in Table III. The material of the rotor sleeve is a titanium alloy. The material of the PM is NdFeB. The prototype is shown in Fig. 12. 


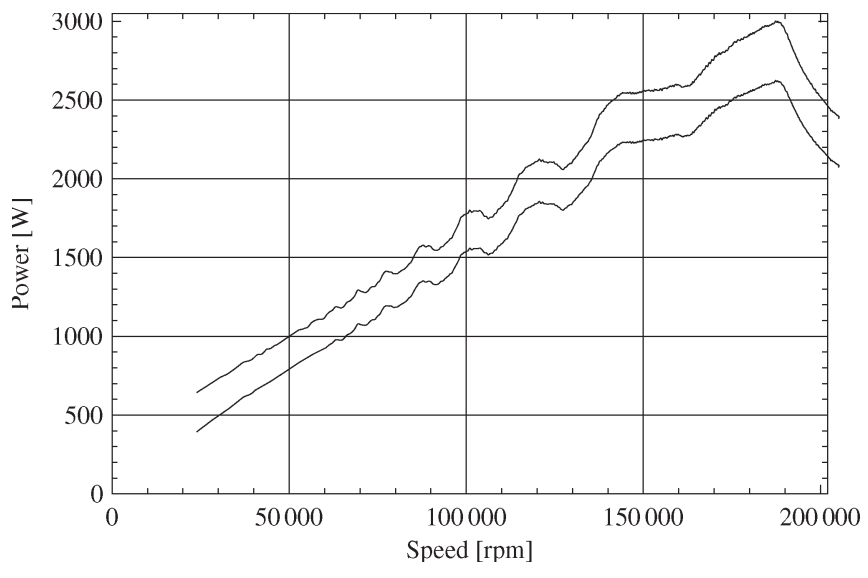

Fig. 13. (Top) measurement of the electrical input electrical power and (bottom) mechanical output power of the VHS slotless PM prototype.

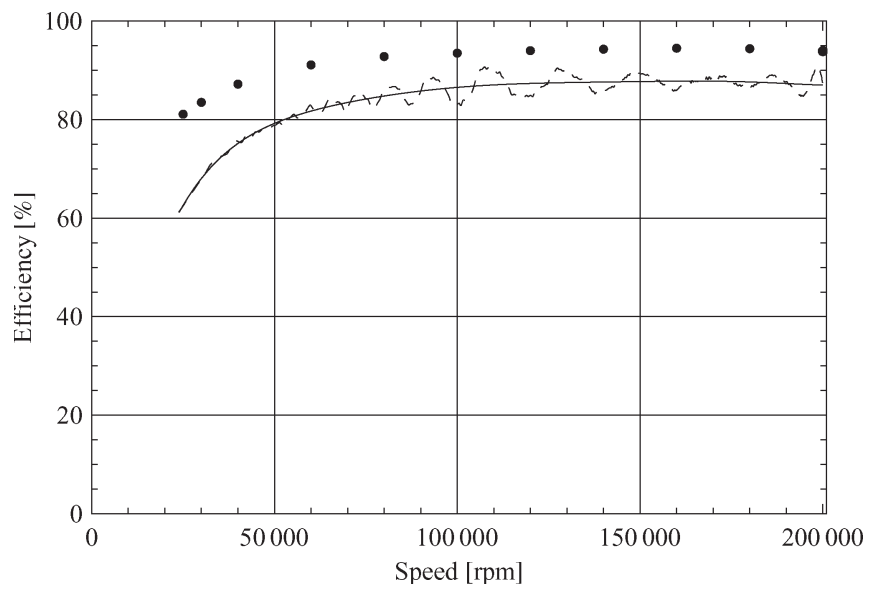

Fig. 14. Efficiency of the VHS slotless PM prototype. The dashed curve represents the ratio between the output torque measured by the presented method and the input power the VHS slotless PM prototype. The continuous curve represents a curve fitting of the dashed curve. The dots represent the analytical model.

\section{B. Measurement of the Optimized Prototype}

A test and measurement bench is used for the acceleration of the VHS prototype. The method presented in Section V filters signals which are significant. The electronic current regulation creates current ripples. Their effect can be seen on the input power shown in Fig. 13. This curve is obtained by averaging over a current period the sum of the instantaneous electrical power in each of the three phases. The dashed line in Fig. 14 represents the efficiency of the VHS prototype calculated by dividing the input power of the prototype by the mechanical output power deduced by the method of Section V. The ripple in this efficiency curve is due to the fact that the torque measurement method filters the effect of the current regulation in the electronics which commands the power bridge. The ripples on the right side are also due to a side effect in the polynomial fitting process. This efficiency curve is averaged using a polynomial function of order eight. The resulting real efficiency is represented as a continuous line also shown in Fig. 14.

The mechanical power output curve shown in Fig. 13 is obtained by multiplying the real efficiency (continuous line shown in Fig. 14) by the input power.
At $200 \mathrm{kr} / \mathrm{min}$, the efficiency is $87.0 \%$ and the output power is $2.19 \mathrm{~kW}$. It takes $244 \mathrm{~ms}$ to accelerate the rotor from 0 to $200 \mathrm{kr} / \mathrm{min}$. The maximum measured speed is $206 \mathrm{kr} / \mathrm{min}$.

\section{Model Validation}

It is important to emphasize that the model is a fit-free model. Every parameter is taken from the literature, material data sheet, or is separately measured.

The 2-D torque model shown in (4) is validated through 2-D finite element methods with an error of less than $0.01 \%$. The measured static torque is $11.2 \%$ lower than the model because of 3-D effects.

Since there are no fitting parameters, the presented model has the advantage to be general. Indeed, any fitting parameter would be geometry dependent or design dependent and lowers the range validity of the model. For this reason, the choice was made not to include any parameters fitted to the measured prototype.

The constraints on the rotor dimensions added by the mechanical model are validated by the fact that the rotor does not break at $200 \mathrm{kr} / \mathrm{min}$.

As shown in Fig. 14, the dots represent the efficiency given by the analytical model. For the power output of $2.19 \mathrm{~kW}$ at $200 \mathrm{kr} / \mathrm{min}$, the efficiency given by the model is $93.9 \%$ instead of the $87.0 \%$ measured. As shown in Fig. 14, we see that although there is a ratio between the theoretical and measured power losses, the curve form is correct.

This confirms that some important theoretical aspect have not been taken into account in the modeling. To improve the model, the following aspects need to be considered.

1) The eddy currents power losses in the rotor produced by the magnetic field created by the current in the coils.

2) The eddy currents power losses in the coils.

3) The iron power losses in the stator yoke due to the field created by the current in the coils.

4) The effect of the 3-D structure on the torque model.

5) The effect of the higher harmonics of current due to the $120^{\circ} \mathrm{ON}$ operation mode inverter. Indeed, in this paper, only the first harmonic is considered, since the currents are assumed to be sinusoidal functions of the time.

\section{CONCLUSION}

The different aspects of the modeling of a VHS PM slotless motor have been presented: the multiphysics analytical model, the optimization, the prototype, the measurements methods, and the comparison between the model and the measurements. The approach shows excellent results: it allowed to overcome the original target of $200 \mathrm{kr} / \mathrm{min}, 2 \mathrm{~kW}$.

The magnetic torque model is in very good agreement with 2-D finite element methods.

The optimization process, which takes in the presented case less than $1 \mathrm{~s}$, allows one to test many different configurations. In particular, Pareto frontiers are calculated. They give a representation of the physics of the motor.

Both the ball bearing measurement method and the motor torque measurement method showed good results. The 
ball bearing friction torque measurement method gives results which are useful for the validation of the total efficiency of the prototype. The motor torque measurement method is successful at $200 \mathrm{kr} / \mathrm{min}, 2 \mathrm{~kW}$. It showed that the model gives a right insight into the physics the PM slotless machine, although there are still missing parts in the power losses model.

The next step which will need to be considered is the rotor losses created by eddy currents, in the PM, in the sleeve, and in the coils.

\section{REFERENCES}

[1] A. Chiba and T. Fukao, "Super high speed electrical machines," in Proc. IEEE Power Eng. Soc. Gen. Meet., 2004, pp. 1272-1275.

[2] L. Zhao, C. Ham, L. Zheng, T. Wu, K. Sundaram, J. Kapat, and L. Chow, "A highly efficient $200000 \mathrm{rpm}$ permanent magnet motor system," IEEE Trans. Magn., vol. 43, no. 6, pp. 2528-2530, Jun. 2007.

[3] J. W. Kolar, C. Zwyssig, and S. D. Round, "Beyond $1000000 \mathrm{rpm}-$ Review of research on mega-speed drive systems," in Proc. 9th COBEP, Blumenau, Brazil, Sep. 30-Oct. 4, 2007.

[4] C. Zwyssig, S. D. Round, and J. W. Kolar, "An ultrahigh-speed, low power electrical drive system," IEEE Trans. Ind. Electron., vol. 55, no. 2, pp. $577-585$, Feb. 2008

[5] N. Bianchi, S. Bolognani, and F. Luise, "Potentials and limits of highspeed PM motors," IEEE Trans. Ind. Appl., vol. 40, no. 6, pp. 1570-1578, Nov./Dec. 2004

[6] N. Bianchi, S. Bolognani, and F. Luise, "High speed drive using a slotless PM motor," IEEE Trans. Power Electron., vol. 21, no. 4, pp. 1083-1090, Jul. 2006.

[7] P.-D. Pfister and Y. Perriard, "Design procedure for a very high speed slotless permanent magnet motor," in Proc. 9th Int. Conf. Model. Simul. ELECTRIMACS, 2008. CD-ROM.

[8] Y. Yamashita, S. Ibaraki, and H. Ogita, "Development of electrically assisted turbocharger for diesel engine," in Proc. 8th Int. Conf. Turbochargers, Turbocharging, 2006, pp. 147-155.

[9] R. Tirnovan, S. Giurgea, A. Miraoui, and M. Cirrincione, "Surrogate modelling of compressor characteristics for fuel-cell applications," Appl. Energy, vol. 85, no. 5, pp. 394-403, May 2008.

[10] I. Takahashi, T. Koganezawa, G. Su, and K. Ohyama, "A super high speed PM motor drive system by a quasi-current source inverter," IEEE Trans. Ind. Appl., vol. 30, no. 3, pp. 683-690, May/Jun. 1994.

[11] L. Zheng, T. Wu, D. Acharya, K. Sundaram, J. Vaidya, L. Zhao, L. Zhou, C. Ham, N. Arakere, J. Kapat, and L. Chow, "Design of a superhigh-speed cryogenic permanent magnet synchronous motor," IEEE Trans. Magn., vol. 41 , no. 10 , pp. $3823-3825$, Oct. 2005.

[12] H. Polinder and M. J. Hoeijmakers, "Eddy-current losses in the segmented surface-mounted magnets of a PM machine," in Proc. Inst. Elect. Eng.-Elect. Power Appl., May 1999, vol. 146, no. 3, pp. 261-266.

[13] M. Morimoto, K. Aiba, T. Sakurai, A. Hoshino, and M. Fujiwara, "Position sensorless starting of super high-speed PM generator for micro gas turbine," IEEE Trans. Ind. Electron., vol. 53, no. 2, pp. 415-420, Apr. 2006

[14] J. D. Park, C. Kalev, and H. F. Hofmann, "Control of high-speed solidrotor synchronous reluctance motor/generator for flywheel-based uninterruptible power supplies," IEEE Trans. Ind. Electron., vol. 55, no. 8, pp. 3038-3046, Aug. 2008.

[15] C. Zwyssig, J. Kolar, W. Thaler, and M. Vohrer, "Design of a $100 \mathrm{~W}$, $500000 \mathrm{rpm}$ permanent-magnet generator for mesoscale gas turbines," in Conf. Rec. 40th IEEE IAS Annu. Meeting, 2005, vol. 1, pp. 253-260.

[16] J. Luomi, C. Zwyssig, A. Looser, and J. W. Kolar, "Efficiency optimization of a $100-\mathrm{W}, 500000$-rpm permanent-magnet machine including air friction losses," in Conf. Rec. 42nd IEEE IAS Anпи. Meeting, New Orleans, LA, Sep. 2007, pp. 861-868.
[17] T. Noguchi and M. Kano, "Development of $150000 \mathrm{r} / \mathrm{min}, 1.5 \mathrm{~kW}$ permanent-magnet motor for automotive supercharger," in Proc. 7th Int. Conf. PEDS, Bangkok, Thailand, Nov. 2007, pp. 183-188.

[18] Z. Xia, Z. Zhu, and D. Howe, "Analytical magnetic field analysis of Halbach magnetized permanent-magnet machines," IEEE Trans. Magn., vol. 40, no. 4, pp. 1864-1872, Jul. 2004.

[19] A. Bazergui, T. Bui-Quoc, A. Biron, G. McIntyre, and C. Laberge, Résistance des Matériaux, 3rd ed. Montréal QC, Canada: Presses Internationales Polytechniques, 2002.

[20] P.-D. Pfister and Y. Perriard, "A 200000 rpm, 2 kW slotless permanent magnet motor," in Proc. 8th ICEMS, Wuhan, China, Oct. 2008, pp. 3054-3059.

[21] P.-D. Pfister, C. Koechli, M. Markovic, and Y. Perriard, "Analysis of hysteresis losses in synchronous permanent magnet motors," in Proc. 12th Biennial IEEE Conf. Electromagn. Field Comput., 2006, p. 144.

[22] J. Vrancik, "Prediction of windage power loss in alternators," NASA, Washington, DC, 1968.

[23] T. A. Harris and M. N. Kotzalas, Rolling Bearing Analysis, vol. I Boca Raton, FL: CRC Press, 2007.

[24] T. A. Harris and M. N. Kotzalas, Rolling Bearing Analysis, vol. II. Boca Raton, FL: CRC Press, 2007.

[25] B. Bossmanns and J. F. Tu, "A power flow model for high speed motorized spindles-Heat generation characterization," J. Manuf. Sci. Eng., vol. 123, no. 3, pp. 494-505, Aug. 2001.

[26] F. Schweizer and K. Adleff, "Rolling bearings in turbocharger application," MTZ, vol. 67, pp. 16-19, 2006.

[27] K. Tanimoto, K. Kajihara, and K. Yanai, "Hybrid ceramic ball bearings for turbochargers," SAE Trans., vol. 109, no. 5, pp. 763-775, 2000.

[28] Pro@DESIGN optimization software. [Online]. Available: http://www. designprocessing.com/

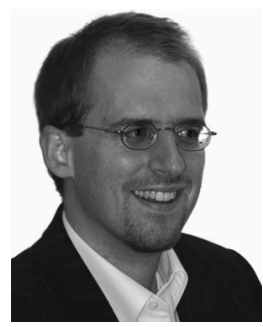

Pierre-Daniel Pfister was born in Bienne, Switzerland, in 1980. He received the M.Sc. degree in physics from the Swiss Federal Institute of Technology, Lausanne (EPFL), Switzerland, in 2005, where he is currently working toward the Ph.D. degree. He studied for one year at the University of Waterloo, Waterloo, ON, Canada.

$\mathrm{He}$ is currently a Development Engineer with Sonceboz SA, Sonceboz, Switzerland, and also with Moving Magnet Technologies SA, Besançon, France. His research interests are in the field of permanent-magnet machines, very-high-speed machines, and analytical optimization.

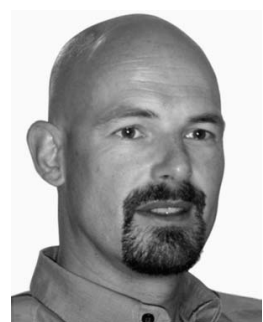

Yves Perriard (M'00-SM'05) was born in Lausanne, Switzerland, in 1965. He received the M.Sc. degree in microengineering and the $\mathrm{Ph} . \mathrm{D}$. degree from the Swiss Federal Institute of Technology, Lausanne (EPFL), in 1989 and 1992, respectively.

Cofounder of Micro-Beam SA, Yverdon, Switzerland, he was CEO of this company involved in high-precision electric drives. Since 1998, he has been with EPFL, first as a Senior Lecturer and, since 2003, as a Professor. He is also currently the Director of the Integrated Actuator Laboratory and the Vice-Director of the Microengineering Institute. His research interests are in the field of new actuator design and associated electronic devices. He is author or coauthor of more than 80 publications and patents. 